\title{
OBSERVACIONES SOBRE ALGUNAS OBRAS DE PABLO VERONÉS Y DE SUS SEGUIDORES EN ESPAÑA (I. PABLO VERONÉS)
}

\author{
POR \\ JOSÉ MARÍA RUIZ MANERO \\ Doctor por la U.A.M.
}

\begin{abstract}
En este artículo se atribuye por primera vez a Pablo Veronés un "San Jerónimo", depósito del Prado, conservado en Zaragoza, y se analizan minuciosamente otras pinturas suyas o relacionadas con él, además de algunas copias, que hasta el momento no habían recibido mucha atención por parte de la crítica.

Palabras clave: Pintura. Siglo xvi. Veronés. San Jerónimo. Museo Prado.

In this article the author for the first time atributes to Paolo Veronese a "Saint Jerome" kept in Zaragoza and carefully anlyses other paintings by him or related to him, and also some copies, which have not been very much considered by art historians.

Key words: Painting. Xvi century. Veronés. Saint Jerome. Prado Museum.
\end{abstract}

No todo lo que existe en España de Pablo Veronés y de sus seguidores ha sido objeto, como observó Pérez Sánchez a propóstito de «Cristo acompañado por los Padres del Limbo visita a su madre», de una adecuada valoración moderna ' ${ }^{2}$ En 1991 Ruiz Gómez publicó su Catálogo de Pintura Veneciana histórica en el Real Monasterio de El Escorial en el que se daba noticia y se estudiaban, además de pinturas ya conocidas, otras que habían pasado hasta el momento inadvertidas. A continuación se presentan una serie de observaciones con las que se pretende contribuir al mejor conocimiento de unas obras que sin duda merecen recibir mayor consideración por parte de la crítica.

Cuenta la Universidad de Zaragoza con un «San Jerónimo» (L. $93 \times 77$ cms) (Fig. 1), depósito del Prado, que, a pesar de su gran calidad, no se tiene noticia que se haya estudiado en profundidad ${ }^{2}$ y que todo hace suponer que sea obra de Pablo Veronés. El modelo de rostro de

\footnotetext{
1 Pérez Sánchez, A. E. «Veronese e la Spagna nel Seicento» en Nuovi studi su Paolo Veronese, Venecia, 1990, p. 96.

Quisiera agradecer a D. ${ }^{a}$ Mercedes Orihuela la ayuda que me prestó para localizar y ver las pinturas del Museo del Prado depositadas en distintas instituciones. También, agradezco a D. Emilio Marcos, director del Museo de Bellas Artes de Asturias, la ayuda que me brindó durante mi visita a Oviedo.

${ }^{2}$ Depositado por R.O. desde 1884. Procede del desaparecido Museo de la Trinidad. (Museo del Prado. Inventario General de Pinturas. II El Museo de la Trinidad (Bienes desamortizados), Madrid, 1991, p. 160, n. ${ }^{\circ} 483$ (inv. act. n. ${ }^{\circ} 7.074$ ) (en la ficha del inventario actualizado figura como «Anónimo español del s. XVII» y en la ficha del inventario de la Trinidad no se atribuye).
} 
nariz ligeramente aguileña, pómulos hundidos, luenga y sedosa barba, profundas entradas que lo convierten en prácticamente calvo, nos habla del maestro de Verona, piénsese en sus San Jerónimos conservados en las iglesias de San Pedro mártir de Murano y de Sant'Andrea della Zirada (en depósito en la Galleria dell'Accademia de Venecia), en la National Gallery de Washington, y en particular en el que figura con un donante en el cuadro conservado en la Dulwich College Pictures Gallery ${ }^{3}$. Los hombros altos y el torso ancho y muy desarrollado, propio de una persona que en su juventud fue fuerte, con los pechos caidos y arrugas en la zona de las axilas, también los utilizó Veronés para las mencionadas representaciones del mismo santo. Además, comparte con el San Jerónimo de Sant' Andrea de la Zirada un mismo sutil nimbo. Incluso su postura no resulta ajena al mundo de nuestro pintor, piénsese en particular en el San José - cuya fisonomía, por otra parte, es muy similar a la del nuestro- que figura en el fresco de la «Madonna della pappa» que adorna la Stanza della lucerna de la Villa Maser. Por lo que respecta al Crucifijo que lleva en la mano, no resulta muy distinto del representado en los citados cuadros de Washington y de Murano, y con el de este último coincide además en la forma del nimbo. También la forma de manejar el pincel resulta típica de Veronés. Suya es la manera de delimitar la figura con una amplia línea marrón que tiende a fundirse con el entorno, de definir con firmes pinceladas los pliegues, de crear la impresión de una barba sedosa sirviéndose de un fondo grumoso sobre el que se destacan unos trazos finos y serpenteantes, de establecer sutilmente con un rico juego de luces y sombras la viveza de las carnaciones. Suyo también es el colorido utilizado, obsérvese el vivo rojo rosáceo del manto del santo, el verde fresco y profundo de la vegetación que se adivina a su derecha, el pardo grisáceo de la roca que cubre parte del fondo del cuadro, el tono ligeramente tostado de la piel del santo. Posiblemente se realizara en la década de 1560, cuando su estilo en plena madurez se manifiesta grandilocuente y majestuoso. Es a inicios de dicho periodo cuando pinta los frescos de la Villa Masser y a partir de 1565 sus últimas obras de la iglesia de San Sebastián ${ }^{4}$, conjuntos éstos con los que nuestro San Jerónimo comparte un gusto por la representación dignamente ampulosa.

Al haber formado parte del extinguido Museo de la Trinidad, cabe suponer que perteneció a algún convento o iglesia de Madrid que sufrió la desamortización. Por otra parte, quizás no sea aventurado pensar que antes de llegar a España pudo encontrarse en la iglesia de San Sebastián de Venecia, en donde Ridolfi (1648) cita: «nell'andito nel passare in Sacrestia è picciolo quadretto di San Girolamo», cuadro que Zanetti (1733) sigue mencionando en el mismo lugar, pero que ya Moschini (1815) dice que había sido sustituido por una «misera copia». Aunque en 1956 Suida propuso su identificación con el «San Jerónimo» conservado en la National Gallery de Washington ${ }^{5}$, bien pudiera tratarse del nuestro, máxime si se piensa que éste debió realizarse por los mismos años en los que Veronés ejecutó sus últimas pinturas para dicha iglesia.

A diferencia del fondo, que se encuentra bastante perdido, la figura del santo, a pesar de mostrar algunas reintegraciones, no parece haber sufrido mucho. Además no parece estar muy sucio, ni cubierto con gruesos barnices.

Véanse, también, Cruzada Villaamil, G., Catálogo Provisional historial y razonado del Museo Nacional de Pinturas, Madrid, 1865, p. 72, n. ${ }^{\circ} 483$ (Obra del «Estilo de Pereda»), Angulo Iñiguez, D. y Pérez Sánchez, A. E., Historia de la Pintura Española. Pintura madrileña del segundo tercio del siglo xvil, Madrid, 1983, p. 210 (No es de Antonio de Pereda), ««El Prado disperso»: Cuadros depositados en Zaragoza», Boletín del Museo del Prado, 1995, n. ${ }^{\circ}$ 34, T. XVI, p. 79 («Anónimo español del s. XVII»).

${ }^{3}$ Véase Pignatti, T. y Pedrocco, F., Veronese. L'opera completa, Milán, 1995, T. I, pp. 265-266, T. II, pp. $383-385$ y 403.

${ }^{4}$ Véase Pignatti y Pedrocco, op. cit., 1995, T. I, pp. 174-228, y 268-269.

${ }^{5}$ Cf. Pignatti y Pedrocco, op. cit., 1995, T. II, p. 532.

AEA, LXXV, 2002, 297, pp. 5 a 21 

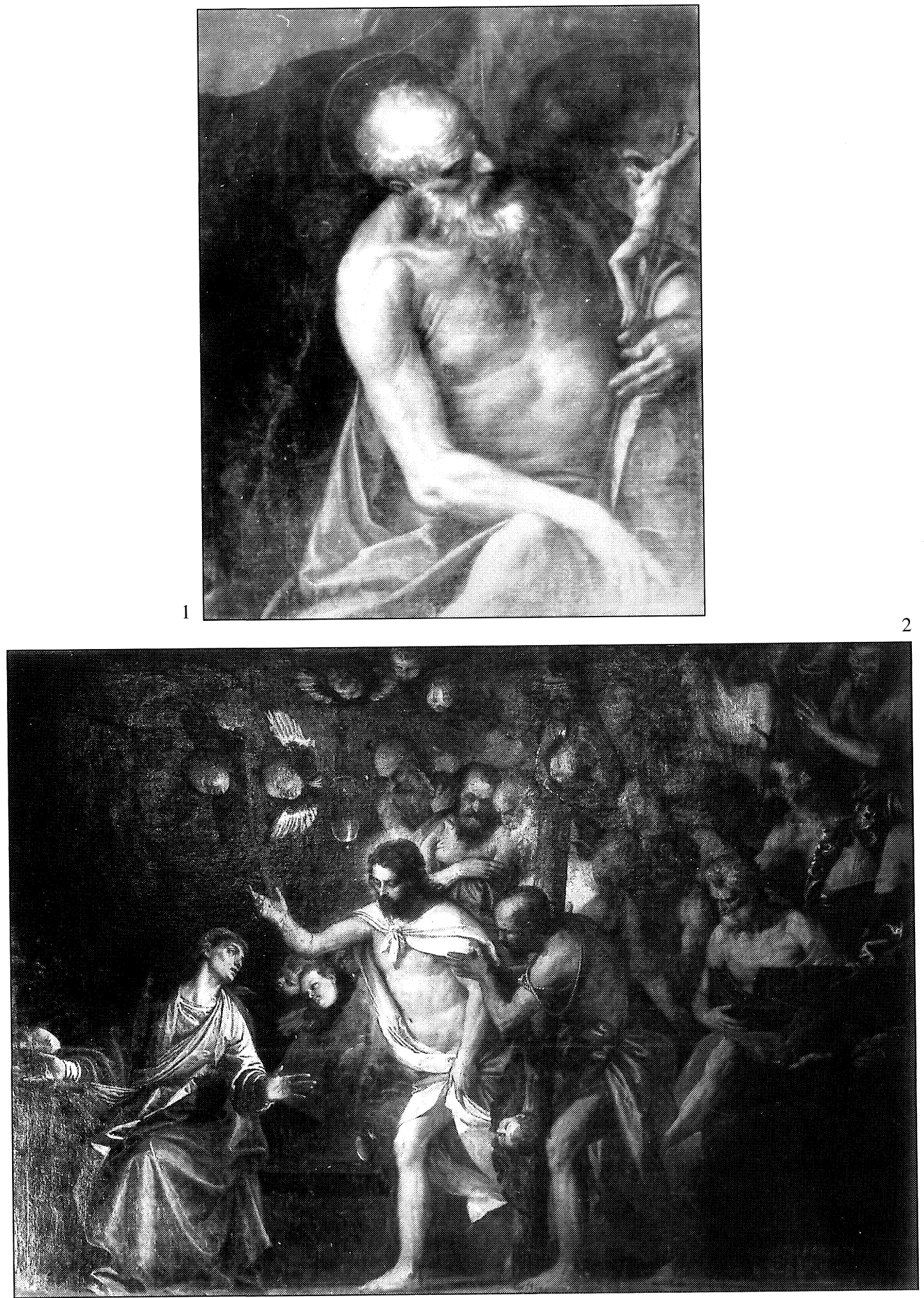

Fig. 1. Pablo Veronés, San Jerónimo. Zaragoza. Universidad.

Fig. 2. Pablo Veronés, Cristo acompañado por los Padres del Limbo visita a su Madre. El Escorial (Madrid). Monasterio (Foto cedida y autorizada por el Patrimonio Nacional).

AEA, LXXV, 2002, 297, pp. 5 a 21 
Cuenta el Monasterio de El Escorial con un magnífico cuadro de «Cristo acompañado por los Padres del Limbo visita a su Madre» (L. $159 \times 218 \mathrm{cms}$ ) (Fig. 2), el cual, atribuido de antiguo a Veronés, aunque Justi ${ }^{6}$ lo citó a su nombre y Pérez Sánchez ${ }^{7}$ puso de manifiesto, como se ha dicho, que no había todavía recibido una adecuada valoración moderna, ha sido ignorado por los autores de las recientes monografías y catálogos críticos de nuestro pintor. Recientemente Ruiz Gómez ${ }^{8}$ lo estudió. Si se albergare alguna duda, bastará para disiparla con observar el vigor, seguridad y maestría que muestra en su ejecución. Como puso de manifiesto Ruiz Gómez, la Virgen y Cristo son «claros modelos veronesianos». También nos habla de nuestro pintor tanto el trazo firme y sin vacilación con que el pincel va creando las formas como la variedad y nobleza de expresiones que animan los rostros de sus dignos y solemnes personajes. Si, como acertadamente puso de manifiesto Sánchez Cantón ${ }^{9}$, no se aprecian en esta obra «ni arquitecturas ni composición espectacular, ni telas ricas y joyas», ello en absoluto debe hacernos dudar, como hizo a dicho historiador, de que se trate de obra de su mano, pues Pablo Veronés, a medida que se iba acercando al final de su vida, fue interiorizando paulatinamente su lenguaje pictórico depurándolo de excesos y haciéndolo cada vez más intimista y piadosamente sincero. $Y$ es entonces cuando habría que situar a nuestra pintura, en la última década de su vida, momento en que se aprecia en sus obras una tendencia a simplificar los escenarios, a concentrar la tensión dramática en la acción que se narra, a hacer que el colorido, sin perder magnificencia, se haga más austero y comedido. Piénsese al respecto en el «Lavatorio de los piés» de la Národní Galerie de Praga o en el muy tardío «Milagro de San Pantaleón» (Iglesia de San Pantaleón, Venecia) ${ }^{10}$, cuadros que como el nuestro no poseen espectaculares entornos, cuyo colorido resulta comedidamente sonoro y en los que mediante una sabia elección de elementos y una acertado juego de luces se logra infundir una gran carga emocional y expresiva a la escena.

H. Tietze y Tietze-Conrat ${ }^{11}$ pensaron que cabía la posibilidad de que el siguiente cuadro citado por Ridofi en la vida de Benedetto Caliari fuera el que se conserva hoy en el Escorial: «Il Signor Caliari detto (se refiere a «Giosepe Caliari», «nipote (sobrino) di Paolo Veronese») hà di mano del zio (se refiere a Benedetto Caliari) vn quadro di nostro Signore al Giordano con molte figure, e'l Redentore, che visita la madre dopò la Risurrettione col seguito de'Santi Padri.» ${ }^{12}$. R. Cocke ${ }^{13}$, sin embargo, argumentó que ello no era de ninguna manera posible, porque el cuadro en poder de Gioseppe Caliari se sigue mencionanado en el inventario de la colección de los herederos de Paolo Veronés de 1682 con el número 179 y con las siguientes medidas 9 por 10 «quarte» (traducidas a centímetros 153 por 170), mientras que el cuadro de El Escorial ya lo cita el padre Santos en su edición de 1657 y, además, sus medidas son muy distintas. En el Museo de Bellas Artes de Lille existe un dibujo de la composición estudiada

\footnotetext{
${ }^{6}$ Justi, C., Velázquez y su siglo, Madrid, 1953, p. 625.

${ }^{7}$ Pérez Sánchez, A. E., art. cit., 1990, p. 96.

${ }^{8}$ Ruiz Gómez, L., «Cristo acompañado por los Padres del Limbo visita a su Madre, de Veronés, en el monasterio de El Escorial», Boletín del Museo e Instituto «Camón Aznar», 1987, T. XXIX, pp. 45-48 y op. cit, 1991, pp. 134-136.

${ }^{9}$ Sánchez Cantón, F. J., «La pintura de la escuela italiana en El Escorial», en AA. VV. El Escorial 1563-1963, Madrid, 1963, Vol II, p. 398.

Véase, también, AA. VV. (El Escorial. Octava maravilla ..., Madrid, 1987, fig. 422) (reproducido a nombre de Pablo Veronés), Checa, F.(Tiziano y la monarquía hispánica, Madrid, , 1994, p. 293) (considerado cuadro excluido habitualmente de los catálogos de Veronés).

${ }^{10}$ Fechadas por la crítica hacia 1585 y 1587 respectivamente, véase Pignatti y Pedrocco, op. cit., 1995, T. II, pp. 466469 y $500-501$.

${ }^{11}$ The Drawings of the Venetian Painters in the 15 th and 16 th Centuries, Nueva York, 1979, p. 358.

${ }^{12}$ Ridolfi, C., Le Maraviglie dell'Arte Ouero le Vite de gl'Illustri Pittori veneti, e dello Stato..., Venecia, 1648, Parte prima, p. 345. En el siglo XVIII recogerá las mismas palabras B. Dal Pozzo en su vida de Benedetto Caliari (Le Vite de 'Pittori degli Scultori et Architetti Veronesi..., Verona, 1718, p. 121).

${ }^{13}$ Veronese's Drawings. A catalogue raisonné, Londres, 1984, p. 349.
}

$A E A, \mathrm{LXXV}, 2002,297$, pp. 5 a 21 
que los Tietze consideraron de Benedetto, quizás el «modello» para el cuadro de El Escorial, idea esta última compartida por Meijer, quien además informa que fue considerado por Châtelet (1968) original de Pablo Veronés, y que, por su parte, Cocke lo creyó simplemente una copia no atribuible a Benedetto por su pobreza de ejecución y por seguir con mucha precisión la composición del cuadro de El Escorial. Muy posiblemente, en cambio, como piensa Meijer ${ }^{14}$, el dibujo de Van Dyck (conservado en su cuaderno de viaje que es propiedad hoy del British Museum de Londres) que reproduce con bastante fidelidad parte de la composición estudiada, sí se hiciera a partir de la versión citada por Ridolfi.

Ya señaló Justi que fue regalado a Felipe IV por Juan Alfonso Enríquez de Cabrera, Almirante de Castilla, lo que por lo demás consta en su inventario de 1647: «Otro marco dorado con niños plateados en que estaba el lienzo de la Aparicion de Nro. Sr., de mano del Veronés, que se dió al Rey Nro. Sr. ...1.100 (reales)» ${ }^{15}$. En 1657 el padre Santos lo describe con palabras elogiosas en el Aula de Escritura del monasterio de El Escorial: «Sobre el sepulcro, encima de la Capilla està vn Lienço de Paulo Veronès, en que Christo acompañado de los Padres del Limbo, visita à su Madre... La inuencion es rara; el capricho nueuo; y el concierto, y armonia de lo historiado, superior al encarecimiento. Las Figuras son menores que el natural» ${ }^{16}$.

Tietze y Tietze-Conrat ${ }^{17}$ mencionan una versión posterior en el Wohltätigkeitshaus en Baden, cerca de Viena, versión que se reproduce en Oesterreichische Kunsttopographie, 18, p. 92, fig. 144.

En España se tiene noticia de dos copias. Una, que figura en la «Liquidación, división y partizión de los vienes, efectos y demás hazienda que quedó por fin y muerte de Don Theodoro Ardemans,...» (documento fechado en 1733): «Otro quadro, copia de Pablo Beronés, de Christo quando se apareció resuzitado con los Santos Padres a Nuestra Señora, de vara y quarta de alto y vara y media de ancho (traducido a centímetros $104,5 \times 125,25$ ), con marco negro y perfiles dorados 240 (se entiende reales) $\gg^{18}$, y otra, citada por Ponz en la sacristía del convento de monjas de Santo Domingo de Loeches, que, por lo que parece desprenderse de sus palabras, debía de ser obra de un pintor que trabajó para Felipe IV: «... estos dos cuadros que acabo de referir son, ciertamente, excelentes copias de algunos de los grandes artífices que tuvo Felipe IV a su servicio, porque están hechos con jugo, manejo y con los demás caracteres que constituyen

\footnotetext{
14 «Per la fortuna di Paolo Veronese fino al 1664» en Cat. Exp. Veronese e Verona, Verona, 1988, pp. 113-114.

${ }^{15}$ Fernández Duro, C., El último Almirante de Castilla Don Juan Tomás Enríquez de Cabrera, Duque de Medina de Rioseco, Conde de Módica, Osona, Cabrera y Melgar; Señor de las villas de Castroverde, Aguilar, Rueda y Mansilla, etc, Madrid, 1903, pp. 210-211.

${ }^{16}$ Santos, Francisco de los, Descripcion breve del Monasterio de S. Lorenzo El Real del Escorial, Madrid, 1657, fol. 71v

En el siglo xviI, siempre como obra de Veronés y en la misma Aula de Escritura, la seguirán mencionando el padre Ximénez (Descripción del Real Monasterio de San Lorenzo del Escorial, Madrid, 1764, fol. 118) y Ponz (op. cit., 1788, T. II, Carta IV n. $^{\circ} 71$ (edic. 1988, Vol. I, p. 405)). El 1 de noviembre de 1809 fue trasladada por Quilliet de El Escorial a Madrid: «VERONÉS Jesús sacando las almas del Purgatorio» (en el cajón n. ${ }^{\circ}$ 26) (Hempel Lipschutz, I., «El despojo de obras de arte en España durante la Guerra de la Independencia», Arte Español, 1961, p. 244) y el 14 de mayo de 1813 se llevó del exconvento del Rosario a la Academia de San Fernando: «N. 109. Vn quadro de 7 palmos y 8 dedos de alto por 10 y 4 de ancho. Representa la Aparición de Christo á la Santa Virgen y Santos Padres; autor Pablo Veronés.» (V.V., «Manuel Napoli y la colección de cuadros del exconvento del Rosario», Revista de Archivos, Bibliotecas y Museos, 1904, noviembre, p. 195.) En 1820, ya de nuevo en El Escorial, Bermejo (Descripción artística del Real Monasterio de San Lorenzo del Escorial y sus preciosidades despues de la invasion de los franceses, Madrid, 1820, p. 236) lo menciona, con el número 2 , en la habitación en la que siempre había estado desde el siglo xvir. En 1857 lo cataloga, siempre como obra de Pablo Veronés, V. Poleró (Catálogo de los cuadros del Real Monasterio de San Lorenzo, llamado del Escorial ..., Madrid, 1857, p. 49, número 108 (número, en blanco, que sigue conservando en su ángulo inferior izquierdo) y en 1861 lo cita A. Rotondo (Descripción de la Gran Basílica del Escorial, Madrid, 1861, p. 174, ${ }^{\circ}$ 108). Desde 1966 se encuentra en los Nuevos Museos de El Escorial, y en el lugar en el que figura actualmente, Salas Capitulares, desde 1986 (Ruiz Gómez, op. cit., 1991, p. 136).

${ }_{17}$ Tietze y Tietze-Conrat, op. cit., 1979 , p. 358.

${ }^{18}$ Agulló Cobo, M., «Noticias sobre pintores madrileños de los siglos Xvı y XVII», en Documentos inéditos para la Historia del Arte. I., Granada, Universidad de Granada y Autónoma de Madrid, , 1978, p. 206.
} 
un cuadro original. Lo mismo digo de dos cuadros de Pablo Veronés que hay en la sacristía de esta iglesia; es, a saber: la Aparición de Cristo resucitado a María Santísima y acompañado de los padres que estaban en el limbo, repetido del que hay en la pieza de la Aulilla,... ambos de Pablo Veronés» ${ }^{19}$. A propósito de esta última el Duque de Berwick y de Alba dice que perteneció a la Casa de Olivares, que era obra de Pablo Veronés, que sus medidas eran vara y media de alto por tres varas y media de ancho (traducido a centímetros $125,25 \times 292,25$ ) y que fue sustraida de Loeches por Sebastiani ${ }^{20}$. Por su parte, Pérez Sánchez ${ }^{21}$ pensó que quizás fuera de la mano de Juan Bautista Martínez del Mazo, quien se sabe que copió a Pablo Veronés.

También en El Escorial se conserva «El Padre Eterno y el Espítitu Santo» (L. 61,5 × 76,5) (Fig. 3), cuadro que, a pesar de que el padre Sigüenza dijo que era de Pablo Veronés ${ }^{22}$, ha sido ignorado por la crítica. Recientemente Ruiz Gómez lo ha estudiado ${ }^{23}$.

Al figurar sólo el Padre Eterno, el Espíritu Santo y unos angelitos, el padre Sigüenza supuso que se trataba de un «remate de alguna pintura o cuadro donde estaba pintado el Hijo» y en nuestros días Ruiz Gómez que quizás fuera un fragmento de algun cuadro de la Coronación de la Virgen o de la Trinidad. Podría también pensarse que tal vez formara parte de una representación de la «Anunciación», piénsese en el cuadro de este asunto y autor que se conserva en el mismo monasterio de El Escorial.

Aunque no se diga el autor, todo hace suponer que corresponda a: «Otra pintura al ollio sobre lienço de Dios Padre, en su marco, con molduras doradas y negras; que tiene de alto honze dozabos y de ancho vna bara y vna ochaua (traducido a centímetros 75,9 $\times 94$ ), que se tomó de la almoneda de Jacobo de Trezo» (entregada por Felipe II a El Escorial el 8 de julio de 1593) ${ }^{24}$. Curiosamente, ni el padre Santos ni el padre Ximénez la citan. Debió dejar El Escorial durante la francesada, ya que el 14 de mayo de 1813 se trasladó del exconvento del Rosario a la Academia de San Fernando ${ }^{25}$. En 1820 ya se encontraba de nuevo en El Escorial, pues Bermejo la cita, con el número 27, en la Sacristía. En el mismo lugar la mencionan, siempre a nombre de Pablo Veronés, Poleró y Rotondo ${ }^{26}$.

Entre los cuadros depositados por el Museo del Prado en el Museo del Ampurdán de Figueras (Gerona) figura uno de «Jesús y el centurión» (L. $143 \times 136)^{27}$ (Fig. 4), cuya composi-

${ }^{19}$ Ponz, A., Viaje de España, en que se da noticia de las cosas mas apreciables, y dignas de saberse, que hay en ella, 1787, T. I, Carta VI, n. 22 ( edic. Madrid, 1988, Vol. I, p. 248-249).

${ }^{20}$ Berwick y de Alba, Duque de, Discurso de ingreso del Duque de Berwick y de Alba en la Academia de San Fernando, Madrid, 1924, p. 92.

${ }^{21}$ Art. cit., 1990, p. 101

${ }^{22}$ Sigüenza, F. José de, op. cit., 1605 (Parte Segunda, Discurso XVII, edic. 1986, p. 373) (lo cita en su celda).

${ }^{23}$ Ruiz Gómez, op. cit., 1991, pp. 132-133 (da noticia de su presencia en el Monasterio desde el padre Sigüenza y mantiene su atribución a Pablo Veronés).

${ }^{24}$ Zarco Cuevas, F. Julián., «Inventario de las alhajas, relicarios, estatuas, pinturas, tapices y otros objetos de valor y curiosidad donados por el rey Felipe II al Monasterio de El Escorial. Años 1571 a 1598.», Boletín de la Real Academia de la Historia, 1930, Vol. 97, p. 49.

${ }^{25}$ «N. 47. Vn quadro del P. Eterno, de una vara de alto por tres quartas de ancho (traducido a centímetros $83,5 \times 63$ posiblemente por error se puso que medía de alto lo que medía de ancho y viceversa); original del Veronés.» (V.V., art. cit., 1904, p. 193).

Cabe la posibilidad de que, a pesar de atribuirse a Mateo Cerezo, corresponda a: «MATEO CARRESO. El Padre Eterno» (en el cajón n. ${ }^{\circ}$ 19), cuadro trasladado por Quilliet de El Escorial a Madrid el 1 de noviembre de 1809 y que debe ser el mismo que el que figura en una lista publicada por Madrazo de obras traídas de El Escorial y del Palacio de San Ildefonso : «M. CEREZO Padre Eterno», que, a su vez, se menciona en otra lista de obras enviadas durante aquellos años a San Ildefonso: «CEREZO El Padre Eterno.» y que debió trasladarse a Madrid de San Ildefonso por Real Decreto de 15 de octubre de 1810: «M. CEREZO El Padre Eterno.» (Hempel Lipschutz, art. cit., 1961, pp. 241, 248, 249 y 250).

${ }^{26}$ Bermejo, op. cit., 1820, p. 90 . Poleró, op. cit., 1857, p. 45, n. 89 (número que todavía conserva en su ángulo inferior izquierdo). Rotondo, op. cit., 1861, p. 80.

${ }^{27}$ Depositado por O.M. desde 1948. (Museo del Prado. Inventario General de Pinturas. I La Colección Real, Madrid, 1990, p. 179, n. ${ }^{\circ} 625$ (inv. act. n. ${ }^{\circ} 493$ ) (Pablo Veronés (ficha del inventario de 1857). Discípulo de Veronés (ficha del inventario actualizado)).

$A E A, \mathrm{LXXV}, 2002,297$, pp. 5 a 21 
ción en líneas generales reproduce invertida la parte principal del cuadro de Pablo Veronés del mismo asunto conservado en el Museo del Prado (n. ${ }^{\circ}$ 492). Los cambios más importantes introducidos con respecto a éste son: Cristo dirige su mirada a sus acompañantes y no al centurión, el personaje que se encuentra en el cuadro del Prado a la izquierda de Cristo de pie (¿San Pedro?) aparece en la obra de Figueras agachado y en su lugar es un joven (¿San Juan?) quien dirige la mirada al centurión, el acompañante que con sofisticado tocado asoma detrás de Cristo y el africano que con amplio turbante cierra la composición de Madrid se han sustituido por dos personajes barbados.

Resulta difícil afinar mucho en su atribución, ya que se encuentra recubierta de gruesas capas de barnices, que impiden apreciar el colorido original, y su parte inferior está pasmada, no resultando visible parte de la composición. Por lo que puede observarse, frente a las composiciones autógrafas de Veronés, manifiesta ésta cierta torpeza, al aparecer los personajes comprimidos en un reducido espacio sin haberse logrado establecer entre ellos, como generalmente hace nuestro pintor, amplios y cadenciosos ritmos. Además, resulta algo monótona y cansina la forma de organizar la escena alineando a las figuras en dos grupos: el constituido por los soldados, el centurión, el personaje barbado a los pies de Cristo y los dos personajes detrás de éste a su izquierda, todos los cuales se encuentran inclinados hacia la derecha, y el formado por el personaje de espaldas, Cristo y el joven que se encuentra detrás de él a su derecha, que lo están hacia la izquierda. Pero si la composición, a pesar de su indudable vinculación veronesiana, resulta algo floja, su ejecución, por lo que puede observarse bajo las gruesas capas de barniz, muestra una pincelada segura, muy fluida, larga y ágil que recuerda a Veronés. Asimismo, su colorido da la impresión de ser muy vivo. Su estado actual no permite decir nada concluyente, por lo que por el momento cabe preguntarse si, a pesar de sus debilidades de composición, nos encontramos ante un Pablo Veronés o más bien, si se trata de obra realizada en su taller bajo su supervisión y en la que intervino el maestro o si, por el contrario, se debe a alguno de sus discípulos siguiendo su estilo. Esperemos que una cuidada restauración permita despejar incógnitas.

Perteneció al marqués del Capio, ya que figura entre las obras de su colección que pasaron a la corona: «Veronés: El Centurion 11.000 rs.» ${ }^{28}$. Sin duda se trata del cuadro n. ${ }^{\circ} 386$ de $\mathrm{Pa}$ blo Veronés del centurión de más de dos varas de alto por menos de dos varas de ancho (traducido en centímetros $+167 \times-167)$ mencionado en el inventario de dicho aristócrata de 1688 y al margen de cuyo asiento se dice «S Magd» ${ }^{29}$. También se cita en una «Relación de las Pinturas que habia en el obrador de los Pintores de Cámara de Palacio en 10 de Agosto de 1694...» entre las «Pinturas que se tomaron de la almoneda del Marques del Carpio»: «Vna pintura en lienzo, de Nuestro Señor con el Centurión de dos baras de alto y cerca de dos de ancho, original de Pablo Verones: marco dorado» ${ }^{30}$. En el inventario del Alcázar de 1700 figura en el mismo lugar con el número 613, aunque con medidas algo menores «Siette quarttas en quadro» (traducido en centímetro $147 \times 147)^{31}$.

Véase, también, Caliari, P., Paolo Veronese..., Roma, 1888, p. 267 y 379 (Pablo Veronés), Gaya Nuño, J. A. «Notas al Catálogo del Museo del Prado. (El Prado disperso e inédito)», Boletín de la Sociedad Española de Excursiones, 1954, T. LVIII, p. 116 (Pablo Veronés), «El «Prado disperso»: Cuadros depositados en Figueras (Gerona)», Boletín del Museo del Prado, 1991, n. 30, T. XII, p. 109 (Anónimo veneciano del siglo XVI).

${ }^{28}$ Saltillo, marqués del, «Artistas madrileños (1592-1850). II Pintores y Pinturas», Boletín de la Sociedad Española de Excursiones, 1953, p. 236.

${ }^{29}$ Burke, M. B., Private collection of Italian art in the seventeenth Century Spain, Universidad de Nueva York, 1984, Vol. II, p. 256.

${ }^{30}$ Por lo que respecta a los inventarios reales no publicados, que se encuentran en el Palacio Real de Madrid, se citan las copias que de ellos hizo Sánchez Cantón y que se conservan en el Museo del Prado y en el Instituto Diego Velázquez del C.S.I.C (Madrid).

${ }^{31}$ Fernández Bayton, G., Inventarios Reales. Testamentaría del Rey Carlos II 1701.1703, Madrid, 1975, T. I, p. 79.

$A E A, \mathrm{LXXV}, 2002,297$, pp. 5 a 21 


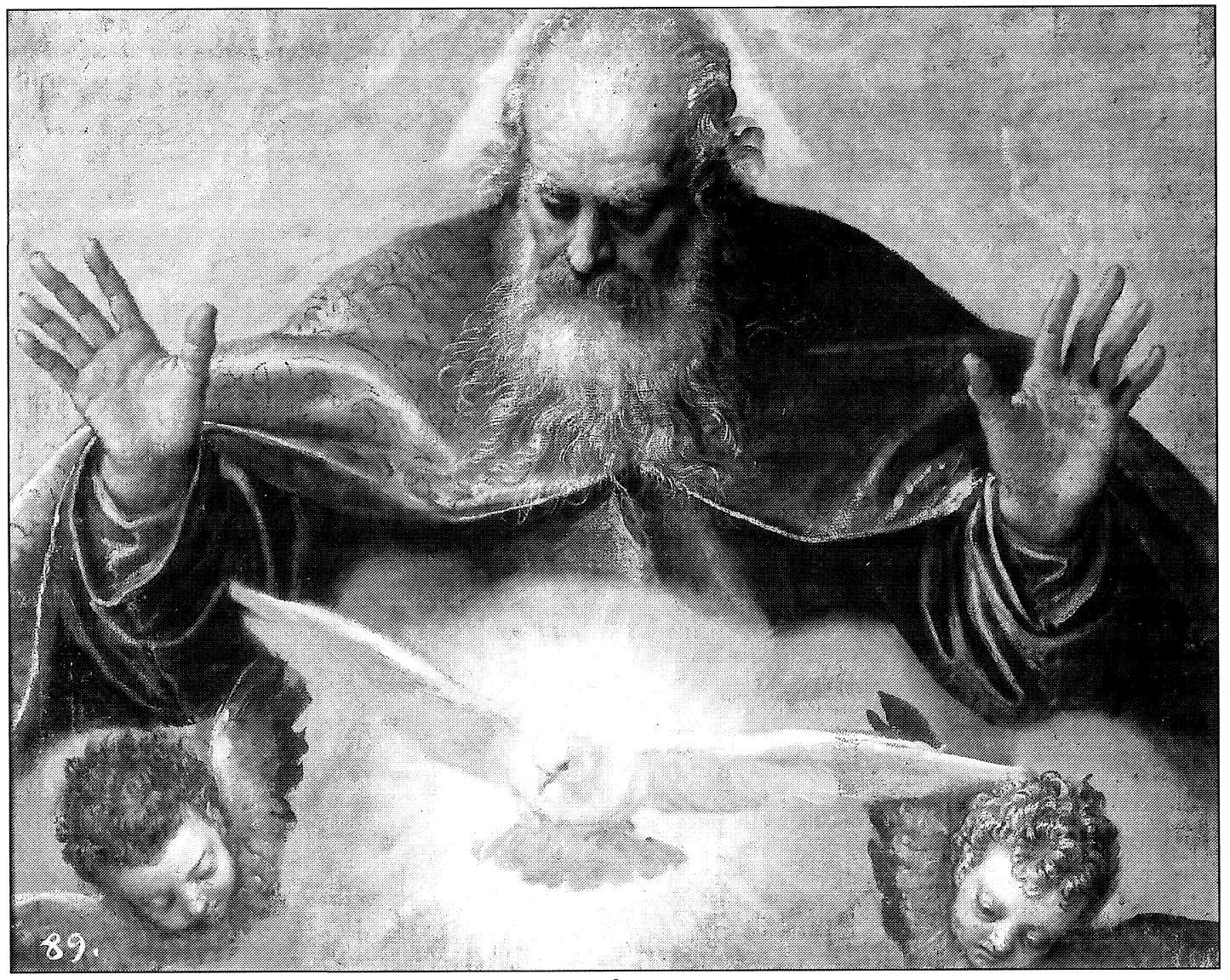

4

3
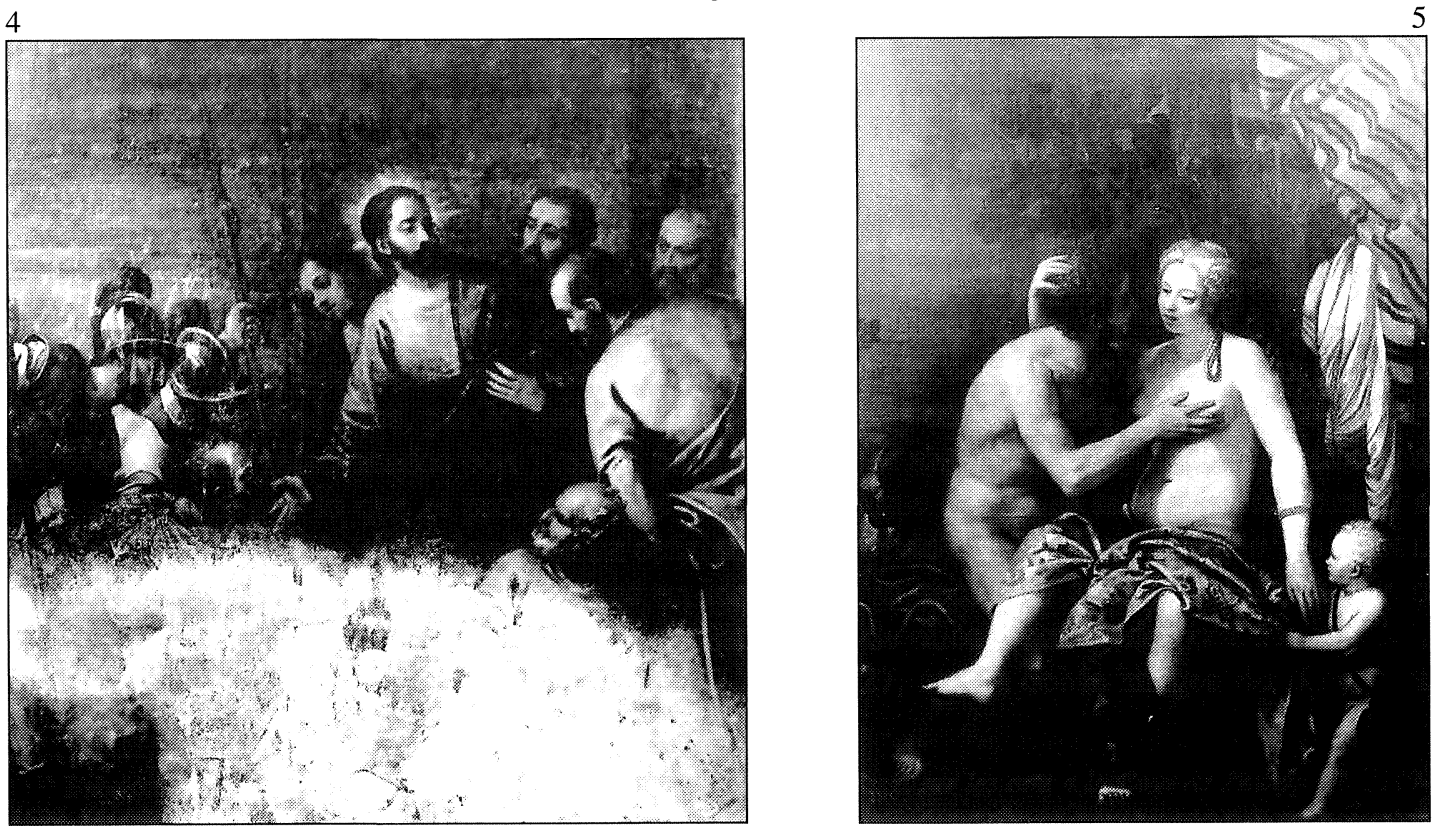

Fig. 3. Pablo Veronés, El Padre Eterno y el Espíritu Santo. El Escorial (Madrid). Monasterio (Foto cedida y autorizada por el Patrimonio Nacional).

Fig. 4. Pablo Veronés (?), Jesús y el centurión. Figueres (Gerona). Museo del Ampurdán.

Fig. 5. Pablo Veronés (?), Venus y Adonis. Madrid. Museo del Prado.

$A E A, \mathrm{LXXV}, 2002,297$, pp. 5 a 21 
En el Museo del Prado se conserva un cuadro de «Venus y Adonis» $(\text { L. } 158 \times 117 \mathrm{cms})^{32}$ (Fig. 5) en pésimo estado de conservación, por lo que tampoco resulta posible atribuirlo con propiedad. Con ligeras variaciones repite la composición de la pintura de Veronés del mismo asunto conservada en el Kunsthistorisches Museum de Viena ${ }^{33}$. Sus diferencias más importantes son: la tela que cubre parte de sus fondos es algo distinta, en la obra de Madrid se han suprimido los perros que en la de Viena se hallaban a la derecha de Adonis y en su lugar se ha colocado al can que en éste estaba a la izquierda de Venus, varía la inclinación de la cabeza del amorcillo situado en ambos cuadros junto a la diosa y, además, por lo que respecta al amorcillo de Madrid, aparece desprovisto de alas. Algunas partes mejor conservadas muestran una seguridad y viveza de trazo que recuerdan al maestro, véase en particular la magnífica cabeza del perro, la tela que cubre las piernas de la diosa o la fina y chispeante pulsera de ésta. Otras, en cambio, parecen resueltas de forma más tosca, obsérvese por ejemplo la tela rayada de color naranja que figura en el ángulo superior derecho del cuadro. Así pues, no parece legítimo descartar con rotundidad bien que sea obra suya, bien que se pintara en su taller con su intervención o bien que se trate de una copia con variaciones del cuadro de Viena realizada por alguno de sus seguidores.

Se sabe por un memorial presentado por Alonso Cano que, junto con Velázquez, hizo éste un viaje a Castilla la Vieja (Martí y Monsó con mucho criterio pensó que fueron a Valladolid) para elegir pinturas para el palacio del Buen Retiro ${ }^{34}$, por lo que pudiera tratarse de la siguiente que consta en el inventario del Palacio de la «Ribera» de Valladolid de junio de 1607 en el «tercer aposento»: «Otro (se refiere a "lienço") de Vn marte y Venus, originales de paulo berones, de dos baras (traducido a centímetros 167)» ${ }^{35}$, pintura que , a su vez, se cita en el inventario del mismo Palacio de 1615 en el «Quarto Aposento»: «Otro, de vn Marte y Venus, de a dos baras, es de Paulo Verones». Sin duda figura en el inventario del Alcázar de 1666 en «la galeria baja del jardin de los emperadores»: 698 - vara y media de alto vara y quarta de ancho de Adonis y Venus de mano de Paulo Verones en 600 dus. de plata». Se sigue mencionando en el mismo lugar, que entonces se denomina Bóvedas del Tiziano, en los inventarios de dicho

Se salvó del incendio del Alcázar, ya que figura en el inventario del Real Palacio de Madrid de 1734: «239 - Otro de vara y dos tercias y media de alto y vara y dos tercias de ancho (traducido en centímetros $153 \times 139,1$ ) con marco dorado liso del Centurion de la escuela de Pablo Veronés» y en el de 1747 del mismo Palacio entre las «Pinturas antiguas» en la «primera Sala de este Oficio»: «33 - Otro lienzo pintura original de Cristo con los Apotoles y el Centurion que le pide vaya a su casa original de Pablo Verones de vara y media en quadro (traducido a centímetros $125,25 \times 125,25$ ) $=$ en 9 mil reales». En 1772 se encontraba en el «Despacho del Rey» del Palacio del Buen Retiro: «3 - Cristo quando el Centurion le suplica vaya a su casa a curar vn enfermo vara y media en quadro Verones». Siempre en el Buen Retiro, lo cita Ponz en un pasillo que va desde un oratorio particular del rey a la pieza que llaman del Despacho: «El del centurión a los pies de Cristo es de Pablo Veronés» (op. cit., 1793 (Tercera impresión), T. VI, Real Sitio del Buen Retiro, n. 36 (Madrid, 1988, Vol. 2, p. 288)). En el inventario de 1789 del Palacio Real de Madrid figura en la «Pieza de paso al dormit. $^{\circ}$ de la S. ${ }^{a}$ Ynfanta»: «3 Siete quartas en quadro (traducido en centímetros $147 \times 147$ ): El Centurion postrado á los Pies de Cristo. Pablo Veronès: en ... 3.500» (Fernández-Miranda, F., Inventarios Reales. Carlos III 1789-1790, Madrid, 1988, Vol. I, p. 53).

${ }^{32}$ Estuvo depositado en la Casa-Museo Colón de las Palmas de Gran por O. M., desde 1940 hasta el 27 de noviembre de 1997 que volvió al Museo del Prado. (Museo del Prado. Inventario General de Pinturas. I..., Madrid, 1990, p. 621, n. ${ }^{\circ} 2363$ (inv. act. $\mathrm{n}^{\circ}$ 5204)).

Véase, también, «"El Prado disperso": cuadros depositados en Las Palmas de Gran Canaria», BMP, 1992, T. XIII, número 31, p. 88 (como «Anónimo italiano S. Xvi»), Checa, op. cit., 1994, p. 293 (la considera de P. Veronés y piensa que pudiera tratarse del cuadro de este asunto traído por Velázquez de Venecia y del que habla Palomino, cuadro este último generalmente identificado con el n. ${ }^{\circ} 482$ del Museo del Prado).

${ }^{33}$ Pignatti y Pedrocco, op. cit., 1995, T. II, pp. 389-390.

${ }^{34}$ Martí y Monsó, J., «Diego Velázquez y Alonso Cano en Castilla la Vieja», Boletín de la Sociedad Castellana de Excursiones, 1904, pp. 333-337 (fecha el viaje en 1635) y Wethey, H.E., Alonso Cano. Pintor, escultor y arquitecto, Madrid, 1983, p. 189 (lo fecha hacia 1640).

${ }^{35}$ Florit, J.M., «Inventario de los cuadros y otros objetos de Arte de la quinta real llamada «La Ribera» en Valladolid», Boletín de la Sociedad Española de Excursiones, 1906, T. XIV, p. 156. 
palacio de 1686 y de $1700^{36}$. Se salvó del incendio que destruyó la residencia de los Austrias ${ }^{37}$. En el inventario del Nuevo Palacio de Madrid de 1772 lo encontramos en el «Estudio de don Andres de la Calleja Pintor de Cámara de su magd.», también conocido como la casa de Reveque: «120 - Otro de Venus y Adonis con Cupido original de Verones», lugar en donde lo verá Ponz ${ }^{38}$. En 1785 fue restaurado por Maella ${ }^{39}$ y quizás fue entonces cuando se le sometió a una brutal intervención que tuvo como consecuencia que se decapitara a Venus y se borrara su figura sustituyéndola por una lira. Prueba de ello es que, por una parte, en el inventario del Palacio Real de Madrid de 1814 se mencione en la casa de Reveque: «Dos tercias en cuadro (traducido en centímetros 55,6 $\times 55,6$ ), cabeza de una Venus = Pablo Verones» - cuadro que, a pesar de la diferencia de medidas, sin duda corresponde al n. ${ }^{\circ} 2.593$ del inventario del Museo del Prado de 1857: «Pablo Veronés 2.593 Cabeza de una Venus. Alto 1 pie, 5 pulg., 6 lin; ancho 1 pie, 5 pulg, 6 lin (traducido en centímetros 40,5 × 40,5)» y del que se dice que pertenecía al $n^{\circ} 2.363$ del mismo inventario y que se «le ha impuesto a su figura correspondiente $»^{40}$ $\mathrm{y}$, por otra, que en el inventario general de los cuadros de S.M (Fernando VII) existentes en la Galeria del Real Museo de 1833 conste en la «Sala reservada»: «37 - Adonis abrazado a Venus cuya figura ha sido borrada y sustituida por una lira -Verones- $6.000 »$.

En el Palacio de la Granja de San Ildefonso (Segovia) se conserva una «Magdalena penitente» (L. $146 \times 113 \mathrm{cms}$ ) (Fig. 6) que, con todas las reservas a las que obliga su estado de conservación, pues está muy oscurecida, pudiera tratarse de una réplica, del taller de Veronés con intervención del maestro, del cuadro del mismo asunto conservado en el Museo del Prado (n. ${ }^{\circ}$ de catálogo 498). Aunque reproduzca de manera bastante literal dicho original -incluso figura en el libro, como en el original, la misma fecha en números romanos: MDLXXXIII-, no deja de poseer algunas diferencias: en el ejemplar de la Granja la santa coge con su mano izquierda su manto en vez de su cabellera, la posición de su cabeza se ha variado ligeramente... Sin embargo, lo que les hace más distintos es sin duda el cambio de la expresión de su rostro. La mezcla de doloroso arrepentimiento y encendido amor que muestra la del Prado, se ha tornado en profundo ensimismamiento teñido de una dulcemente tierna melancolía. Y es en el rostro, además de la cabellera y la parte desnuda de la santa, donde Veronés pudo intervenir, ya que en todas estas partes parece adivinarse bajo la suciedad una excelente factura propia del maestro. Obsérvense las sutiles pinceladitas con las que ilumina con golpes de luz el rostro de la santa, la variedad de tonos de los que se sirve para representar su piel, la clara línea marrón

36 «Otra de vara y media de alto y quarta de ancho de Adonis y Venus de mano de Pablo Verones» (Inventario de 1686) (Bottineau, Y. - quien lo identifica con el citado en 1666-, «L'Alcazar de Madrid et l'inventaire de 1686. Aspects de la Cour d'Espagne au Xvire siècle», Bulletin Hispanique, 1958, T. LX, n. ${ }^{\circ} 3$, p. 322.).

«493 Yttem Ottra de Vara Y media de altto y Vara y quartta de ancho de adonis y Venus de mano de Pablo Berones Con marco negro tassada en Quinienttos doblones ....500» (Inventario de 1700).

(Fernández Bayton, op. cit., 1975, Vol. I, p. 67 y 1985, Vol. III, p. 449).

${ }^{37}$ En el inventario de 1734 , entre las pinturas del Real Palacio que no perecieron en dicho incendio, se menciona: « 20 - Otra de siete quartas de alto y vara y media de largo con su marco negro de Venus y Adonis original de Pablo Verones bien tratado». Asimismo figura en el inventario del Real Palacio de Madrid de 1747, entre las «Pinturas antiguas»: «120 (número, que en rojo, todavía sigue conservando en su ángulo inferior izquierdo) - Otra pintura de Venus y $\mathrm{Adonis}$ con $\mathrm{Cu}$ pido de menos de dos varas de caida y mas de vara y tercia de ancho (traducido en centímetros $-167 \times 111,3$ ) original de Pablo Verones en 10 mil rs.»

38 Ponz, op. cit., 1793, T. VI, n. ${ }^{\circ} 62$ (Madrid, 1988, Vol. 2, p. 254)

39 Barreno Sevillano, M. L. («La restauración de pinturas de las colecciones reales durante el siglo XVIII», Archivo Español de Arte, 1980, p. 489), a quien se debe la noticia de que un cuadro de Pablo Verones de Venus, Adonis y Cupido que se encontraba desde 1772 en el estudio de Reveque fue restaurado por Maella en 1785, se equivoca al pensar que se trata del cuadro $n^{\circ} 482$ del Museo del Prado, ya que éste último se cita en el inventario de 1772 en el «Paso de Tribuna y Trascuartos»: «1078-41 - Dos quadros de la fábula de Venus y Adonis durmiendo con Cupido que esta agarrado a vno de los perros y la Venus le hace aire con vna banderilla y el compañero de otra fábula de dos varas y media en quadro de Pablo Verones».

${ }^{40}$ Museo del Prado. Inventario General de Pinturas. I..., Madrid, 1990, p. 621 (n..$\left.^{\circ} 2.363\right)$ y p. 679 (n. 2.593 ).

$A E A, \mathrm{LXXV}, 2002,297$, pp. 5 a 21 


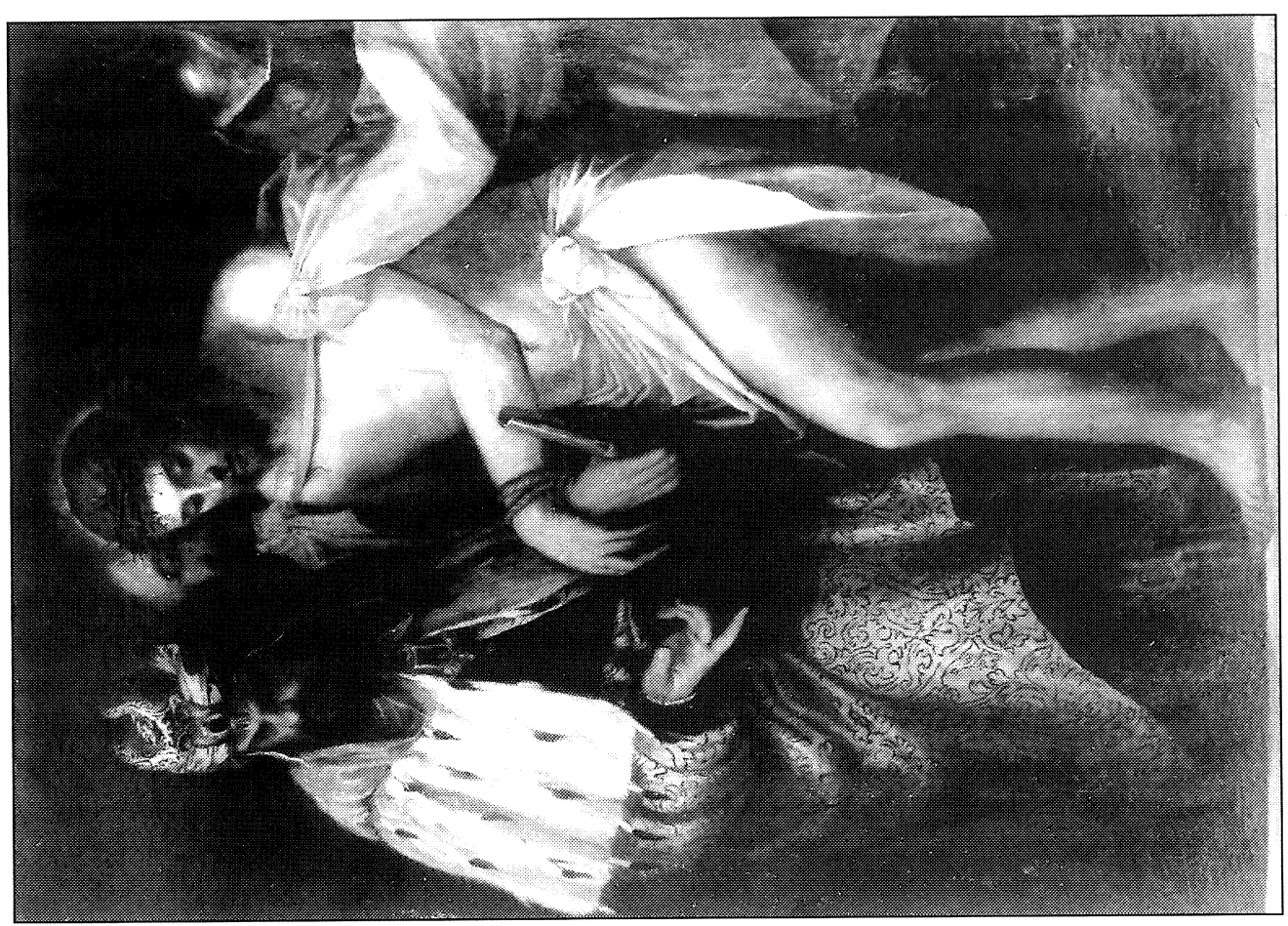

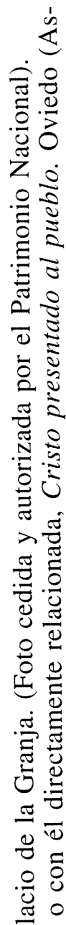

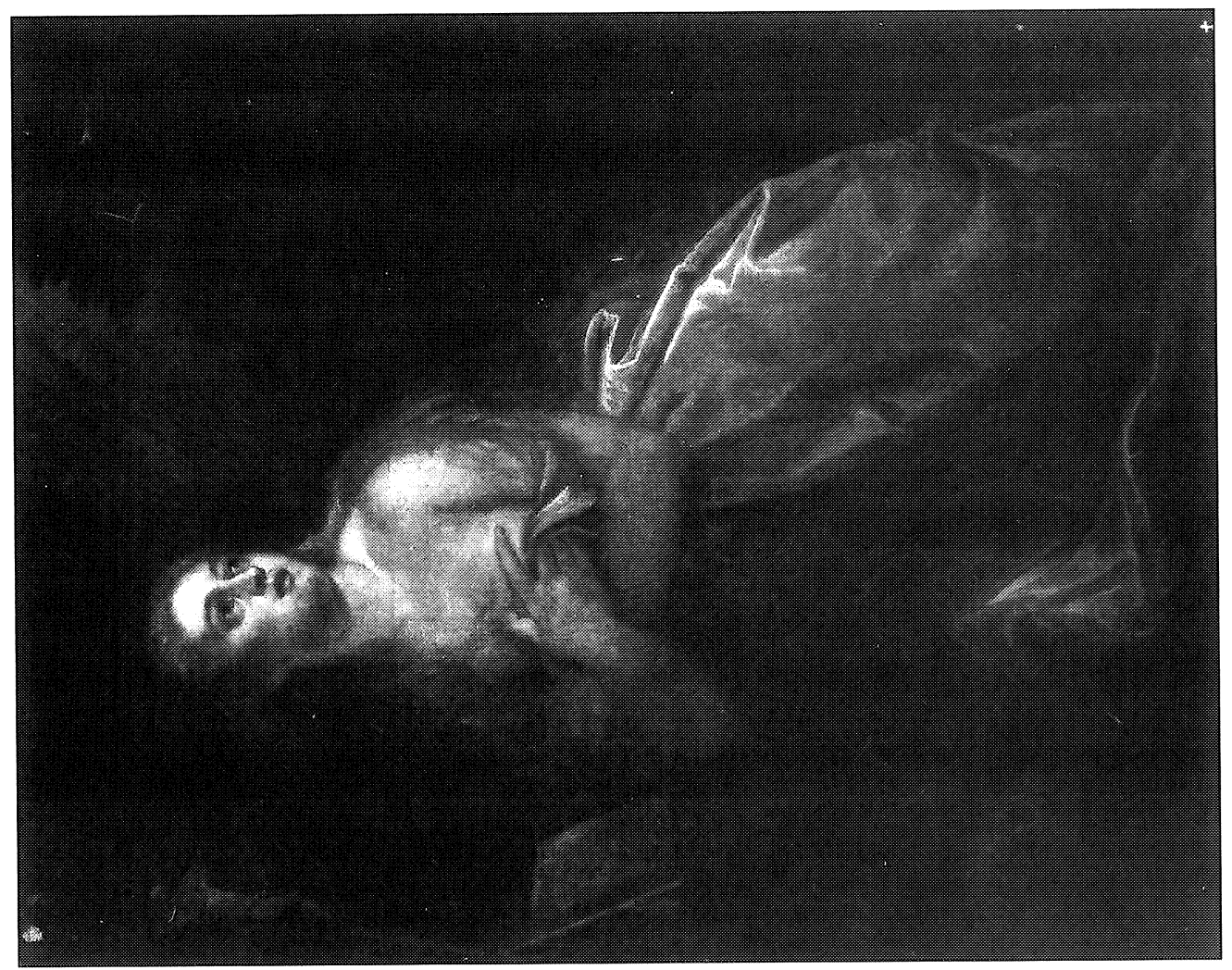

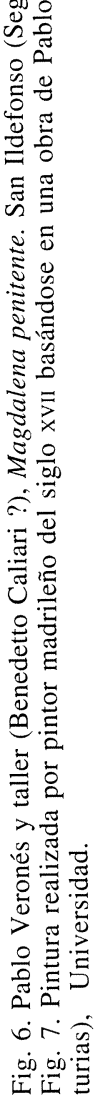

AEA, LXXV, 2002, 297, pp. 5 a 21 
con la que magistralmente dibuja las formas, las trazos dorados muy finos que serpentean en su cabellera. Sin embargo el manto que la cubre, de un color que cabe suponer parecido al del ejemplar del Prado, se diría obra de su taller (Benedetto Caliari (?)), pues, además de seguir de manera bastante literal el original de Madrid, muestra en su ejecución una cierta tosquedad y falta de viveza. En cuanto al fondo nada puede decirse, ya que se encuentra muy oscurecido. Por último conviene destacar que, al ser algo mayor la versión de la Granja, permite conocer la continuación del manto de la santa y observar que ésta está claramente de rodillas. Cabe preguntarse si el cuadro del Prado (L. $122 \times 105$ ) fue en un principio tan grande como el segoviano y si se recortó posteriormente. A ciencia cierta no se sabe, pero en caso de que se haya hecho, ello no pudo producirse después de que pasara a pertenecer a Isabel de Farnesio, pues la flor de lis, marca de su colección, aparece en su ángulo inferior derecho y, si se hubiera recortado con posterioridad, habría desaparecido. Además, las medidas que de éste ofrece su asiento del inventario de la colección de Isabel de Farnesio de 1746 son muy similares a las que tiene en la actualidad: «590 - Vna pintura original en lienzo pegada en tabla de mano de Pablo Verones santa Maria Magdalena con los brazos cruzados vna Cruz vn santo Christo y vna calauera y vn libro de quatro pies y quatro dedos de alto y cinco quartas de ancho (traducido en centímetros $118,5 \times 105) »$.

Perteneció a Isabel de Farnesio, ya que consta en su inventario de La Granja de 1746: «1036 - Otra en lienxo de mao de Pablo Verones duplicada Santa Maria Magdalena de rodillas con las manos cruzadas a el pecho de siete quartas de alto quatro pies y dos dedos de ancho (traducido en centímetros $147 \times 114,9) »{ }^{41}$.

La capilla del edificio histórico de la Universidad de Oviedo cuenta con un hermoso cuadro, «Cristo presentado al pueblo» (L. $166 \times 118)^{42}$ (Fig. 7), depósito del Prado, que puede considerarse obra realizada por pintor madrileño del siglo XVII basándose en una pintura de Pablo Veronés o con él directamente relacionada. Muy típico resulta de Veronés el organizar la escena, tal y como se hace en este cuadro, adoptando un punto de vista bajo que hace necesario escorzar en cierta medida las figuras. Múltiples son las obras que pudieran citarse al respecto, piénsese por ejemplo en las pinturas de las puertas del órgano de San Sebastián de Venecia o en la «Virgen en la gloria con San Sebastián y otros santos» conservada en la misma iglesia ${ }^{43}$. Tanto la fisonomía de Cristo, como su estructura corporal (torso cuadrado y hombros altos), la corona de espinas que ciñe su cabeza y la cinta con la que se cierra su capa recuerdan mucho al «Ecce Homo» de la colección Piero Scarpa de Venecia ${ }^{44}$. Por lo que respecta a su estructura corporal también es muy parecida a la del «Cristo muerto con Nicodemo y un Angel» en depósito en el Museum of Art de Tel Aviv ${ }^{45} \mathrm{y}$, aunque se trate del cuerpo de un anciano, a la del «San Jerónimo» de colección privada veneciana ${ }^{46}$ con la que comparte, además, la manera de disponer el paño de pureza dejando al aire gran parte de la pierna. Por otra parte, la postura de Pilatos resulta muy seme-

\footnotetext{
${ }^{41}$ Se sigue mencionando en los inventarios del referido Palacio de 1774 ( «1036 - Cinco pies y medio de alto por quatro y medio de ancho (traducido en centímetros $153 \times 125,2)$ la Magdalena dicese de $=$ Pablo Veronés= en el quarto del Infante don Antonio= 2.500»), de 1789 («1036 Otra en lienzo de 5 pies y medio de alto, por quatro y medio de ancho marco dorado liso, representa la Magdalena: en dos mil y quinientos reales. Pablo Verones..... 2.500» (Fernández-Miranda, op. cit., 1989, T. II, p. 281)) y de 1814 ( $« 1028$ - cinco pies y medio de alto qatro y medio de ancho la Magdalena = Pablo Verones»). Ponz (op. cit., 1787, T. X, Carta V, n. ${ }^{\circ} 66$ (edic. 1988, Vol. 3, p. 294)) la vió en el «Cuarto de recibir la princesa» de dicho Palacio: «una Santa Magdalena, del (se entiende «estilo») de Pablo Veronés».

${ }^{42}$ Museo del Prado. Inventario General de Pinturas. II ..., Madrid, 1991, p. 147, n. ${ }^{\circ} 435$ (inv. act. n. ${ }^{\circ} 7.033$ ) (en la ficha del inventario actualizado figura como «Anónimo madrileño del siglo XVII»).

Véase, también, Fernández-Castañón Carrasco, J.A. y Marcos Vallaure, E., Cat. Exp. «Juan Carreño de Miranda y la pintura barroca madrileña», Oviedo, 1985, p. 92 (obra de mediados del siglo xvil, dentro del círculo de Rizi).

43 Véase Pignatti y Pedrocco, op. cit., 1995, T. I, pp. 126-129 y 259-260.

44 Véase Pignatti y Pedrocco, op. cit., 1995, T II, p. 491.

${ }^{45}$ Obra considerada de Veronés por parte de la crítica, véase Pignatti y Pedrocco, op. cit., 1995, T. II, p. 406.

46 Véase Pignatti y Pedrocco, op. cit., 1995, T I, p. 246.
}

$A E A$, LXXV, 2002, 297, pp. 5 a 21 
jante a la del David que aparece representado con Betsabé en el cuadro del Museo de Bellas Artes de Lyon ${ }^{47}$ y a la del personaje que figura a la derecha en el dibujo del «modello» para el Martirio de Santa Justina conservado en la colección Devonshire de Chatsworth ${ }^{48}$. Asimismo, por lo que respecta al rico brocado de su manto difícil es negar su sello veronesiano - piénsese en particular en los presentes en «Las Bodas de Canaa» del Museo del Louvre-, y en cuanto a la capilla blanca que le cubre los hombros muy parecida resulta a la del personaje que aparece tras la Magdalena en «La Cena en casa de Simón» (Turín, Galleria Saubada) ${ }^{49}$. Además, el casco del esbirro de la derecha es muy similar al del mismo personaje del «Cristo escarnecido y fustigado» del De Young Memorial Museum de San Francisco ${ }^{50}$. Todas estas coincidencias hacen pensar que en términos generales la invención de esta bellísima composición se deba a Pablo Veronés. Sin embargo, al analizar su ejecución no parece pertenecerle y más bien todo hace suponer que se trate, como se ha dicho, de una obra de pintor madrileño del siglo xviI basada en una creación suya o con él directamente relacionada que, por desconocerse, no se puede afirmar hasta que punto la copie nuestro pintor. Por una parte la piel de Cristo presenta un cierto tono verdoso, inexistente en las obras autógrafas que se conocen de Pablo, así como un aspecto sedoso, liso, fundido y algo relamido que contrasta con la manera más grumosa, aspera y viva con la que éste realiza las pieles. Asimismo, las amplias pinceladas que marcan los pliegues de las vestimentas no muestran la seguridad, prontitud y brío que caracterizan a las hechas por Veronés. Asimismo, a pesar del rojo encendido del manto de Cristo y del amarillo ocre del de Pilatos, presenta el cuadro una cierta tonalidad oscura — que se ve aumentada por la acentuación de las zonas iluminadas y obscuras y por el negro profundo del fondo- que nos separa del maestro de Verona, pues aunque éste en sus últimos años acentuase el juego de luces y sombras, siempre logró embeber a sus personajes en una profunda luz que los hace resaltar con fuerza de la penumbra.

Ahora bien si la composición, como pienso, tiene su origen en Veronés, ¿donde se encuentra o pudo encontrarse en el pasado el cuadro en el que se basó nuestro pintor? En el Escorial, creo poder afirmar, ya que allí existió hasta la francesada un cuadro que se dice de Veronés de un Ecce Homo con figuras de tamaño natural y cuyas medidas no difieren mucho de las de la copia de Oviedo. Las siguientes referencias antiguas prueban lo que se acaba de avanzar. Entre las pinturas compradas en Inglaterra por el Conde de Fuensaldaña (posiblemente durante 1651) y enviadas a España consta: «s. Lorenzo Mas otra muy linda de un exce homo figuras tan grandes como el natural que es de las mejores que a hecho Pablo Veroneus fs. 1200.» Cuadro que cita en 1657 el padre Santos en la Sacristía de El Escorial: «El vltimo por este lado, es vn Ecce Homo, de Paulo Verones, del mismo tamaño («de alto seis pies y medio, y de ancho cinco» (traducido a centímetros 180,8 × 139)). Tambien diò estas con las demas à su Magestad para este fin Don Luis Mendez de Haro» ${ }^{51}$. Se sige mencionando siempre en el mismo lugar en una relación anónima del siglo XVII sobre los cuadros del Escorial: «...un Ecce Homo, figuras al natural, es del Veronés» ${ }^{52}$ y en una relación histórica de las pinturas de El Escorial por

\footnotetext{
47 Véase Pignatti y Pedrocco, op. cit., 1995, T. II, p. 426.

${ }^{48}$ Cocke, op. cit., 1984 , p. 178.

49 Véase Pignatti y Pedrocco, op. cit., 1995, T. I, p. 136.

50 Véase Pignatti y Pedrocco, op. cit., 1995, T. II, p. 497.

51 Vergara, A., «The Count of Fuensaldaña and David Teniers: their purchases in London after the civil war», The Burlington Magazine, 1989, febrero, p. 132. Vergara nos informa de que «s. Lorenzo» es una anotación de Gaspar de Haro, marqués del Carpio, que quiere decir que entonces se encontraba en El Escorial, y de que en el siglo Xvil el padre Santos allí la cita.

Santos, op. cit., 1657 , fol. $45 \mathrm{v}$.

52 Andrés, G. de, «Relación anónima del siglo xvil sobre los cuadros del Escorial», Archivo Español de Arte, 1971, n. ${ }^{\circ}$ 173, p. 58. Pienso que Andrés se equivoca cuando dice que Ponz da la paternidad de esta pintura a Tiziano, pues en realidad lo que hace es citar en la Sacristía, además del «Ecce-Homo de Pablo Veronés», «uno de Ticiano, en que se expresa a
} 
su orden riguroso de colocación hecha en 1776: «30. Pilatos mostrando a Cristo al pueblo .... $\mathrm{O}$ (quiere decir original) Pab. Veronés» ${ }^{53}$. Asimismo, Ponz lo cita siempre en el mismo lugar: «La última pintura es un Ecce-Homo, de Pablo Veronés» ${ }^{54}$. Al no encontrarse actualmente rastro de esta pintura en el Monasterio, todo apunta, como dijo Vega, a que desapareciera durante la francesada. Por su parte, Poleró cita entre los cuadros que en otro tiempo existieron en San Lorenzo: «Pablo Veronés Ecce-homo» ${ }^{55}$.

En cuanto a su procedencia se sabe que perteneció al Museo Nacional de la Trinidad. Al dorso de un reentelado antiguo lleva la siguiente inscripción: «Soy del Espíritu Santo» ${ }^{56}$, lo que parece indicar el lugar en donde se encontraba antes de la desamortización. Al hablar del oratorio del Espíritu Santo de Madrid, dice Ponz: «...hay algunas copias muy buenas de originales de Ticiano, Vacaro, Ribera, etc.» ${ }^{57}$. En el etcétera cabría incluir a Pablo Veronés, pues si bien al no conocerse el original no se puede afirmar que se trate de una copia literal, sin duda se basaba, como se ha dicho, en una pintura del pintor de Verona o con él directamente relacionada.

Por R.O. de 22 de octubre de 1879 se depositó en la Universidad Literaria de Oviedo. Se pensó que había perecido en el incendio de 1934, pero se salvó inverosímilmente, pasando inadvertido a pesar de ocupar un lugar destacado en la capilla universitaria, donde fue localizado por D. Javier G. Santos. Por el inventario de 1854 del Museo Nacional de la Trinidad se tiene noticia de que había sido «Forrado y Restaurado ...» En julio de 1984 se restauró en el Museo de Bellas Artes de Asturias ${ }^{58}$. Por la persona que la restauró se sabe que la preparación del lienzo es de color blanco. Actualmente, su estado de conservación puede considerarse satisfactorio.

Se sigue conservando en el Museo del Prado una «Adoración de los Reyes Magos» (L. 160 $\times 140 \mathrm{cms})^{59}$ (Fig. 8) que es copia muy fiel, posiblemente veneciana y del siglo XVI, del cua-

Pilatos mostrando el Señor al pueblo.» (Ponz, op. cit., 1788, T. II, Carta III, n. ${ }^{\circ} 47$ (edic. 1988, Vol. 1, p. 367)). Asimismo, considero que no existe posibilidad alguna, como sugiere Andrés, de que se trate del «Ecce Homo» atribuido a Veronés que en el momento que se publicó su artículo se encontraba en la Sala IV de los Nuevos Museos de El Escorial. Dicho cuadro pudiera ser un «Ecce-Homo» —en el que figura Cristo con Pilatos y un sayón- que sigue existiendo en los Nuevos Museos, ahora atribuido a Lucca Cambiasso, y cuyo catastrófico estado de conservación dificulta seriamente adivinar quien sea su autor (L. $114 \times 125$, n. $^{\circ}$ inventario 10014564). Eso sí, parece de mano italiana, posiblemente veneciana, de avanzado el siglo xvi. En caso de ser esta obra, la identificación no es posible, porque se trata de una pintura de medias figuras y no de «figuras al natural» (con lo que creo que se quiere expresar figuras de cuerpo entero) como la mencionada en la relación. Por lo que respecta al cuadro hoy en los Nuevos Museos, aunque no correspondan exactamente sus medidas, pudiera ser el siguiente que figura entre los trasladados el 14 de mayo de 1813 del exconvento del Rosario a la Academia de San Fernando: «N. 178. Vn quadro de 4 palmos y 4 dedos de alto por 5 I (¿no será un fallo de impresión y en realidad se trata de 5 I/ 2 , es decir cinco y medio?) de ancho (traducido a centímetros $91,2 \times 115,5$ ) que representa un Eccehomo de medias figuras; su autor Pablo Veronés, estropeado» (V.V., art. cit., 1904, noviembre, p. 108). Cuadro que a su vez posiblemente sea el señalado por Bermejo en el Claustro principal alto del monasterio: «32. Un Ecce-Homo, en donde se ve Pilatos con dos sayones (en nuestro cuadro sólo figura un sayón ¿Se trata de una distracción de Bermejo? o ¿se refiere éste a otro cuadro que no se ha podido localizar? ), figuras de medio cuerpo, por Pablo Veronés» (op. cit., 1820, p. 231). Asimismo, cabe la posibilidad de que se encuentre desde antiguo en las colecciones reales y que corresponda al siguiente que figura en el inventario del Alcázar de 1686 en el Pasillo que llaman de la Madona: «Otra Pintura de vara y media de ancho y mas de vara de alto (traducido en centímetros $=83,5 \times 125,5$ ) que es quando Pilatos mostro al Pueblo a nro Señor de mano de Pablo Verones.» (Bottineau (quien nos informa de su presencia también en el inventario del Alcázar de 1700) , art. cit., 1958, T. LX, n. ${ }^{\circ}$ 2, p. 149) y que en el inventario del mismo palacio de 1700 figura en el mismo lugar atribuido a Tintoretto: «52 Ytten Ottra Pinttura de Vara y media de ancho y mas de Vara de altto que es quando Pilattos mostro al Pueblo a nuestro Señor de mano de tinttoretto tasada en Cientto y Cinquentta Doblones.....» (Fernández Bayton, op. cit., 1975, Vol. I, p. 23).

${ }^{53}$ Vega, A., «Relación histórica de las pinturas de El Escorial por su orden riguroso de colocación hecha en 1776», Documentos para la Historia del Monasterio de San Lorenzo, Madrid, 1962, T. V, p. 249. Vega dice que el cuadro desapareció durante la francesada.

${ }^{54}$ Ponz, op. cit., 1788, T. II, Carta III, n. 47 (edic. 1988, Vol. 1, p. 367)

55 Poleró, op. cit., 1857 , p. 187.

56 Fernández-Castañón Carrasco, J.A. y Marcos Vallaure, E., op. cit., 1985, p. 92.

${ }^{57}$ Ponz, op. cit., 1793, T. V, Quinta División, n. 35 (Madrid, 1988, Vol. 2, pp. 140-141).

${ }_{58}$ Fernández-Castañón Carrasco, J.A. y Marcos Vallaure, E., op. cit., 1985, p. 92.

${ }^{59}$ Estuvo depositado en el Museo de Bellas Artes de Sevilla por O. M., desde 1970 a 1989 (Museo del Prado. Inventario General de Pinturas. I..., Madrid, 1990, p. 303, n. ${ }^{\circ} 1.097$ (inv. act. n. ${ }^{\circ} 489$ ) (en la ficha del inventario de 1857 figura como obra de «Pablo Veronés» y en la ficha del inventario actualizado como «Copia de Veronés»)).

AEA, LXXV, 2002, 297, pp. 5 a 21 

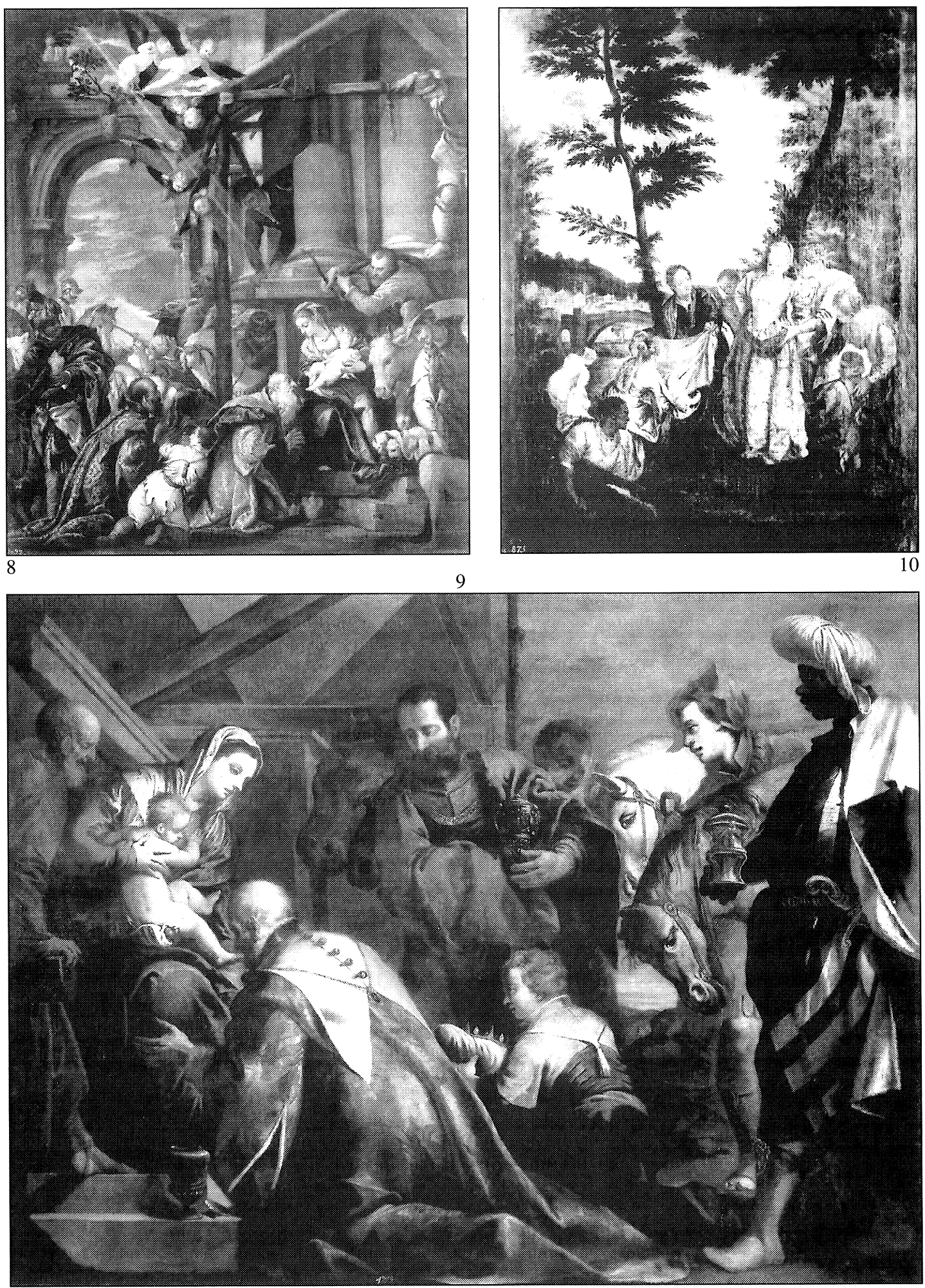

Fig. 8. Pablo Veronés (copia), Adoración de los Reyes Magos. Madrid, Museo del Prado. Fig. 9. Pablo Veronés (copia), Adoración de los Reyes Magos. Madrid, Museo del Prado.

Fig. 10. Pablo Veronés (copia), Moisés salvado de las aguas. Desaparecido en el incendio de la Embajada de España en Lisboa (1975)

AEA, LXXV, 2002, 297, pp. 5 a 21 
dro del mismo asunto perteneciente a la National Gallery de Londres que, a su vez, estuvo en la iglesia de San Silvestro de Venecia ${ }^{60}$. De un colorido rico y vivo, es muy posible que también en este aspecto siga al original.

Desde que Madrazo dijera que «Creen algunos este cuadro de Paolo Farinato» ${ }^{61}$, tanto en los sucesivos catálogos del Prado en los que ha figurado como en varias publicaciones recientes se ha apuntado la posibilidad de que sea obra suya. Sin embargo dudo que le pertenezca, pues en absoluto me recuerda a lo que de él conozco, que en términos generales posee una cierta plasticidad'y gravedad, resultado en parte de su interiorización del lenguaje miguelangelesco, ausente en nuestra pintura. Asimismo, frente a la tendencia a redondear los pliegues de los paños propia de Farinati, sorprenden los trazos quebrados y nerviosos de los que se sirve nuestro copista para realizar las telas. Además, la ligereza y desenfado que muestra en su ejecución hacen que nuestro cuadro produzca una impresión de inquieta vibración ajena a lo que conozco de Farinati ${ }^{62}$.

A propósito de esta pintura escribió Madrazo en 1872: «Parece ser este cuadro el que había en la antesacristía del templo del Escorial y que describió el P. Santos en 1667; su dimensión, sin embargo, resulta algo mayor» ${ }^{63}$. Años después Caliari reprodujo el dato facilitado por Madrazo, aunque sin expresar reserva alguna ${ }^{64}$. Recientemente, tanto Ruiz Gómez como Checa ${ }^{65}$ también pensaron que se trataba de dicho cuadro, que sin embargo pienso que corresponde al n. ${ }^{\circ} 363$ del catálogo de Poleró. Por otra parte, no hay nada que lleve a pensar que la copia del Museo del Prado proceda de El Escorial. En 1828 ya se encontraba en el Museo del Prado: «619 PABLO VERONES. La Adoración de los Santos Reyes. Composición rica en hermosos grupos y figuras bien dibujadas, de excelente colorido. El fondo es un hermoso país con ruinas de Arquitectura y una gloria con graciosos Querubines» ${ }^{66}$. Asimismo se cita en la Testamentaría del rey Fernando VII de 1833, entre los pinturas de su propiedad entonces en el Real Museo, exáctamente en la «Tercera division de la gran Galeria. Entrada a las escuelas francesa y alemana»: «619 - La adoración de los Reyes P. Veronés - 5.000»

En el mismo Museo del Prado también se conserva otra «Adoración de los Reyes Magos» (L. $153 \times 200 \mathrm{cms})^{67}$ (Fig. 9), que es copia parcial con variaciones del cuadro del mismo asunto

Véase, también, Caliari, op. cit., 1888, p. 381 (cita la referencia del Catálogo del Museo del Prado de Madrazo de 1872 en donde figura como obra de Pablo Veronés, aunque se dice que algunos la consideran de Paolo Farinato), Marini, R. y Piovene, G., L'opera completa del Veronese, Milán, 1968, p. 115, n 165 (copia, quizás de Farinati), Pignatti, T., Veronese. L'opera completa, Venecia, 1976, Vol. I, p. 136 (copia antigua, quizás de Farinati), Gould, C., National Gallery Catalogues. The Sixteenth-Century Italian Schools, Londres, 1975 (reimpresión de 1987), p. 319 (copia reducida), Ruiz Gómez, op. cit., 1991, pp. 153-155 (la considera copia de Veronés. Posiblemente la confunda con el cuadro 364 del catálogo Poleró, cuando dice que éste la cita en la Sala Vicarial). Checa, op. cit., 1994, p. 295 (la cree del «Taller de Veronés». Erróneamente piensa que se trata de la pintura n. ${ }^{\circ} 364$ del catálogo de Poleró), Pignatti y Pedrocco, op. cit., 1995, Vol. I , p. 291 (copia antigua, quizás de Farinati).

${ }^{60}$ L. $355 \times 320$. Aunque a menudo la crítica haya pensado que el taller colaboró, parece admitido que tanto su ideación como gran parte de su realización pertenecen al mismo Pablo Veronés. Sobre esta obra, así como sobre copias, dibujos, grabados y pinturas relacionadas con la misma, véanse Marini, R. y Piovene, G., op. cit., 1968, p. 115, n. ${ }^{\circ} 165$; Gould, op. cit., 1987, p. 318-320; Pignatti y Pedrocco, op. cit., 1995, T. I, pp. 291-293.

${ }^{61}$ Madrazo, P. Catálogo descriptivo e histórico de los cuadros del Museo del Prado de Madrid, Madrid, 1872, p. 685, n. 541 .

${ }^{62}$ Por lo que respecta a Paolo Farinati, he visto lo reproducido por Baldissin Molli, G., «Paolo Farinati e gli affreschi della chiesa dei Santi Nazaro e Celso a Verona», Arte Veneta, 1984, Año XXXVIII, pp. 31-45 y consultado AA. VV. La Pittura in Italia. Il Cinquecento, Venezia, 1988, Vol. II, pp. 708-709 (ambas publicaciones citan bibliografía anterior).

${ }^{63}$ Op. cit., p. 685, n. $^{\circ} 541$.

${ }^{64}$ Op. cit., 1888 , p. 251.

${ }^{65}$ Ruiz Gómez, op. cit., 1991, pp. 153. Checa, op. cit., 1994, p. 295.

${ }^{66}$ Eusebi, L., Noticia de los cuadros que se hallan colocados en la Galería del Museo del Rey nuestro señor sito en el Prado de esta Corte, Madrid, 1828, p. 177-178.

${ }^{67}$ Estuvo depositado en el Museo de Murcia por R.O., desde 1882 a 1969

Figura en la O.M. de 1990 en la que se disponía el depósito de varios cuadros en el Museo de Bellas Artes de Asturias, sin embargo, como me comunicó D. ${ }^{a}$ Mercedes Orihuela, nunca se llevó a cabo su traslado (Museo del Prado. Inventario

AEA, LXXV, 2002, 297, pp. 5 a 21 
conservado en la Gëmaldegalerie de Dresde ${ }^{68}$. Presenta los siguientes cambios significativos con respecto a éste: se ha girado al rey mago arrodillado, se ha hecho desaparecer al paje que le sostenía la cola de su capa, al africano que figura frente al caballo blanco del fondo se le ha desprovisto de turbante. Muy probablemente se realizara en el siglo xvII, ya que, por una parte, aparecen acentuados los contrastes entre luz y sombra y, por otra, se ha simplificado la composición haciendo que pierda algo de su carácter suntuosamente aristocrático y lograndose, al mismo tiempo, acercar el misterio representado al espectador. Desgraciadamente se encuentra en muy mal estado de conservación, ya que se aprecian a simple vista pérdidas de capas de pintura y bastantes repintes.

En 1975 pereció en el incendio de la Embajada de España en Lisboa, «Moises salvado de las aguas» (L. $91 \times 72 \mathrm{cms})^{69}$ (Fig. 10), cuadro, depósito del Prado, que a juzgar por la fotografía conservada era copia con algunas variantes del cuadro n. ${ }^{\circ} 502$ del Museo del Prado. Véase al respecto que la figura de la doncella que en el original se recoge graciosamente la falda con la mano derecha mientras mantiene la izquierda alzada se ha sustituido en la copia por una joven desnuda que con ambas manos sostiene una tela con la que se diría que se está secando, que se ha suprimido en la obra perdida la graciosa figurilla colocada en el cuadro del Prado cercana al puente, que son distintas las construcciones de los fondos de ambos cuadros, que en la copia al ser bastante mayor aparecen desarrollados en todos sus bordes los elementos presentes en el original. Por la mayor sequedad que muestra en su ejecución cabría pensar que quizás la realizó un pintor español ${ }^{70}$.

Perteneció a Carlos IV, ya que figura en el inventario de los cuadros que poseía en su Casa de Campo de El Escorial, siendo Príncipe: « Un cuadro, que contiene el Hallazgo de Moisés, cuando la infanta Termutis le hizo sacar del río, de vara y cuarta de alto, y vara de ancho (traducido en centímetros 104, $5 \times 83,5$ ), original de Pablo Veronés. 116 (número que, incompleto, «16» se leía en su ángulo inferior izquierdo)» ${ }^{71}$.

Como se ha podido comprobar con este artículo, son muchos los originales y copias de Veronés que hasta el momento no se han tenido suficientemente en cuenta. Esperemos que lo aquí escrito sirva para avanzar en el conocimiento del maestro de Verona.

General de Pinturas. I...., Madrid, 1990, p. 705, n. ${ }^{\circ} 2.695$ (inv. act. n. ${ }^{\circ} 3.867$ ) (en la ficha del inventario de 1857 figura como obra de «Escuela Flamenca» y en la ficha del inventario actualizado como «Taller de Veronés»)).

Gaya Nuño , J.A.(Historia y Guía de los Museos de España, Madrid, 1968, p. 581) la menciona como «atribuida a Veronés».

${ }^{68}$ Véase Pigatti y Pedrocco, op. cit., 1995, T. I, pp. 279-280.

${ }^{69}$ Depositado por R.O, desde 1919 (Museo del Prado. Inventario General de Pinturas. I...., Madrid, 1990, p. 245, n. ${ }^{\circ}$ 875 (inv. act. $n .^{\circ}$ 503) (en la ficha del inventario de 1857 figura como de «Escuela de PABLO VERONÉS» y en la ficha del inventario actualizado como «Copia de VERONÉS»).

Gaya Nuño, J. A. (art. cit., 1954, T. LVIII, p. 117) la mencionó como copia de Pablo Veronés.

${ }^{70}$ Desde poco después de su llegada a España el original de Pablo Veronés (Museo del Prado, $\mathrm{n}^{\circ}$ 502) debió ser copiado por pintores españoles. Muy probablemente lo reprodujeran tanto la siguiente pintura que figura en la tasación de los bienes del pintor Francisco Ricci (agosto 1685) y que Pérez Sánchez (art. cit., 1990, p. 99) pensó que, aunque no se diga el autor, quizás no fuera aventurado pensar que se debiera al mismo Ricci: «- otro del mismo tamaño («tres quartas», es decir $63 \mathrm{cms}$ ) historia de moyses sin moldura copia de pablo beronese, 50 rs.» (Barrio Moya, J. L., «Los bienes del pintor Francisco Ricci», Archivo Español de Arte, 1983, n²21, p. 42) como la copia de un cuadro de Moisés de Veronés valorada en treinta reales que figura en el inventario y tasación de los bienes que quedaron a la muerte de Claudio Coello (Saltillo, marqués del, art. cit., 1953, p. 201). Quizás se tratara de una de estas dos copias o de otra distinta la siguiente que consta en la tasación, realizada por el pintor D. José Bueno en 1840, de los cuadros que pertenecieron a D. Serafín García de la Huerta: «771 Lienzo. - Moisés sacado de las aguas, copia de Pablo Veronés, tres cuartas de alto por dos de ancho (traducido en centímetros $63 \times 42$ ), en seiscientos reales.» (Saltillo, marqués del, «Colecciones madrileñas de pinturas: La de Serafín García de la Huerta (1840)», Arte Español, 1950-51, T. XVIII, p. 201).

71 Zarco Cuevas, Fray Julián, «Cuadros reunidos por Carlos IV, siendo Príncipe, en su Casa de Campo de El Escorial», Religión y Cultura, 1934, p. 38.

AEA, LXXV, 2002, 297, pp. 5 a 21 